\title{
PHYSICAL PROPERTIES OF HAFNIUM-SILICATE TRANSISTOR GATE DIELECTRIC STACKS AFTER THERMAL PROCESSING
}

Brendan Foran ${ }^{1}$, Todd Rhoad ${ }^{1}$, Michael Campin ${ }^{1}$, Mark Clark ${ }^{1}$, Guoda Lian ${ }^{1}$, Charlene Johnson ${ }^{1}$, Gennadi Bersuker ${ }^{2}$, \& Pat S. Lysaght ${ }^{2}$

${ }^{1}$ ATDF, 2706 Montopolis Dr. Austin, TX 78741

${ }^{2}$ SEMATECH, 2706 Montopolis Dr. Austin, TX 78741

email: Brendan.Foran@ATDF.com

Hafnium-silicate films under development to replace $\mathrm{SiO}_{2}$ gate-dielectrics in semiconductor devices show interesting structural properties that influence electrical performance. Besides the commonly known issues involving the formation of a metaldeficient oxide underlayer previously observed for $\mathrm{HfO}_{2}$ and other metal-oxides, further structure is derived when silicate films are exposed to thermal cycles required for device processing [1]. Similar to previous results for metal organic chemical vapor deposition (MOCVD) silicates [2,3], atomic layer deposited (ALD) films, which appear homogeneous and amorphous as deposited, phase separate when annealed to form composite films with $\mathrm{HfO}_{2}$ crystallites ( $\sim 5 \mathrm{~nm}$ average diameter) suspended in a lower density amorphous matrix that is near to $\mathrm{SiO}_{2}$ in composition. However, this microstructure may also account for mid-gap states which could give rise to charge trapping centers [4].

ALD Hafnium-silicate films were prepared with concentrations ranging from 45 to 75 mol.\% $\mathrm{SiO}_{2}$. All samples received a $700{ }^{\circ} \mathrm{C}$ post-deposition anneal treatment in $\mathrm{N}_{2}$ ambient for 60 seconds. After capping with poly-silicon, half of the samples saw additional anneals at $1000{ }^{\circ} \mathrm{C}$. Plan-view TEM samples were prepared by chemically etching substrate silicon and capping poly-silicon layers with warm $\mathrm{KOH}$. Second Ion Mass Spectroscopy and cross-sectional TEM indicated that the etch had little affect on the thickness and structure of the high-k layer. Figure 1 exhibits high-angle annular dark-field scanning transmission electron microscopy (HAADF-STEM) plan-view images of a $60 \%$ mol. $\mathrm{SiO}_{2}$ ALD hafnium-silicate after $\mathrm{N}_{2}$ anneal at $1000{ }^{\circ} \mathrm{C}$ for 60 seconds. Figure 2 exhibits plan-view images of a $75 \% \mathrm{~mol} . \mathrm{SiO}_{2}$ hafnium-silicate film annealed to $700{ }^{\circ} \mathrm{C}$ indicating evidence of partial ordering at $700{ }^{\circ} \mathrm{C}$ (at left) and complete crystallization and agglomeration after annealing at $1000{ }^{\circ} \mathrm{C}$ (at right). Selected area electron diffraction from large areas of the $1000{ }^{\circ} \mathrm{C}$ annealed samples exhibited ring patterns that were indexed to the monoclinic phase of $\mathrm{HfO}_{2}$ (not crystalline silicate).

In contrast to the plan-view micrographs, cross-sectional TEM images of these films appear to be continuous since the roughness and phase-separation length scale is significantly shorter than the thickness of most TEM samples.

The above observations help to explain trends in the electrical characteristics of transistors built with similar hafnium silicate films as gate dielectrics [5]. 
[1] H. Kim, and P.C. McIntyre, J. Appl. Phys., 92, 5094 (2002).

[2] S. Stemmer, Z. Q. Chen, C. G. Levi, P. S. Lysaght, B. Foran, J. A. Gisby, and J. R. Taylor, Jpn. J. Appl. Phys., 42, 3593 (2003).

[3] S. Stemmer, Y. Lu, B. Foran, P. S. Lysaght, S. K. Streiffer, P. Fuoss, S. Seifert, Applied Physics Letters, 83, 3141 (2003).

[4] R. Ludeke, P. Lysaght, E. Cartier,E. Gusev, M. Chudzik, B. Foran and G. Bersuker, J. Vac. Sci. Technol B, 22, 2113 (2004).

[5] A. R. Brown, J. R. Watling, A. Asenov, G. Bersuker, and P. Zeitzoff, IEEE Trans SISPAD 2005 (in press).
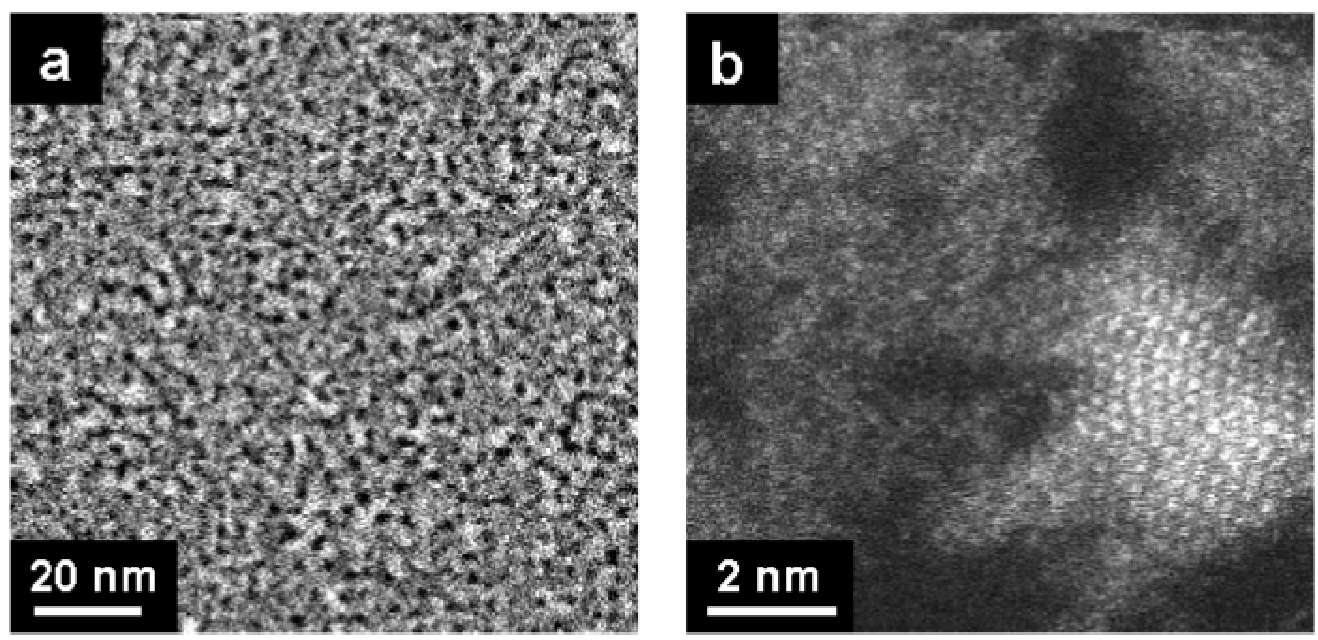

Figure 1. High-angle annular dark-field scanning transmission electron microscopy (HAADF-STEM) plan-view images of a $60 \% \mathrm{SiO}_{2}$ ALD hafnium-silicate after $\mathrm{N}_{2}$ anneal at $1000 \mathrm{C} 60$ seconds. The two images are the same region of the same sample imaged at different magnifications.
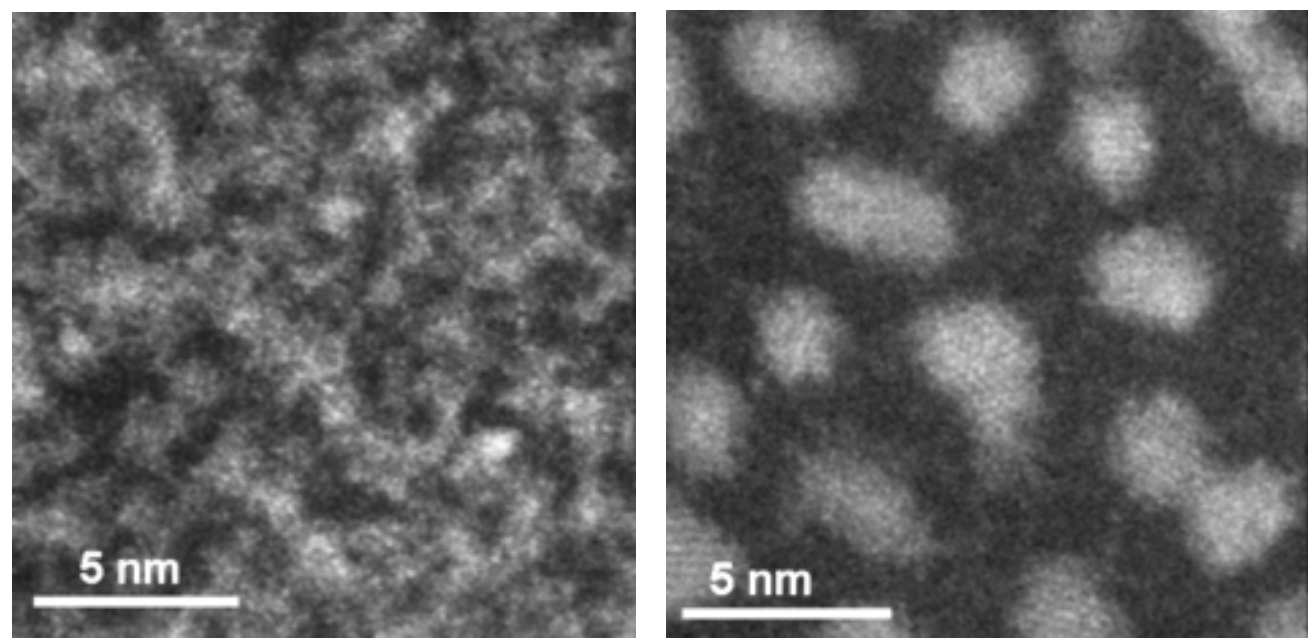

Figure 2 . HAADF-STEM plan-view images of a $75 \% \mathrm{SiO}_{2}$ hafnium-silicate film after annealing at $700 \mathrm{C}$ (at left) and after further annealing at $1000 \mathrm{C}$ (at right). These two images were recorded at the same magnification. 